\title{
Enhanced transduction of polymer photonic crystal band-edge lasers via additional layer deposition
}

\author{
Smith, Cameron; Christiansen, Mads Brøkner; Buss, Thomas; Kristensen, Anders
}

Published in:

2010 Conference on Lasers and Electro-Optics (CLEO) and Quantum Electronics and Laser Science Conference (QELS)

Publication date:

2010

Document Version

Publisher's PDF, also known as Version of record

Link back to DTU Orbit

Citation (APA):

Smith, C., Christiansen, M. B., Buss, T., \& Kristensen, A. (2010). Enhanced transduction of polymer photonic crystal band-edge lasers via additional layer deposition. In 2010 Conference on Lasers and Electro-Optics (CLEO) and Quantum Electronics and Laser Science Conference (QELS) (pp. 1-2). IEEE.

\section{General rights}

Copyright and moral rights for the publications made accessible in the public portal are retained by the authors and/or other copyright owners and it is a condition of accessing publications that users recognise and abide by the legal requirements associated with these rights.

- Users may download and print one copy of any publication from the public portal for the purpose of private study or research.

- You may not further distribute the material or use it for any profit-making activity or commercial gain

- You may freely distribute the URL identifying the publication in the public portal 


\title{
Enhanced transduction of polymer photonic crystal band- edge lasers via additional layer deposition
}

\author{
Cameron L.C. Smith, Mads B. Christiansen, Thomas Buß, Anders Kristensen \\ Department of Micro- and Nanotechnology, DTU Nanotech, Technical University of Denmark, DK-2800 Kongens Lyngby, Denmark \\ Corresponding author: anders.kristensen@nanotech.dtu.dk; Phone: +45-4525 6331, Fax: +45-4588 7762
}

Claus H. Nielsen, Niels B. Larsen

Department of Micro- and Nanotechnology, DTU Nanotech, Technical University of Denmark, DK-4000 Roskilde, Denmark

\begin{abstract}
We present the concept of enhanced transduction for polymer photonic crystal lasers by deposition of an additional polymer layer with selective gas response. We report a significant increase in sensitivity to changes in gas concentration. (C) 2010 Optical Society of America OCIS codes: (230.5298) Photonic crystals; (310.6860) Thin films, optical properties
\end{abstract}

\section{Introduction}

Photonic crystals (PhCs) offer unprecedented nano-scale control of light, having been shown to steer, slow and/or prevent electromagnetic propagation. As such, PhCs have been widely investigated for sensing applications in a number of different architectures [1, 2], with one configuration in particular - the PhC cavity - generating considerable research interest in recent years [3-5]. PhC intra-cavity sensing designs generally rely on detecting the changes in effective refractive index (ERI) of a liquid analyte [6]; however, detecting changes in a gas is difficult with refractive index-based schemes as the variations in gas indices are very small when compared to liquids. In this work we report a polymer-based $\mathrm{PhC}$ intra-cavity sensing approach that utilizes an additional absorptive polymer layer that selectively expands when exposed to specific contents in a gas. We present a numerical and experimental study that demonstrates large changes in ERI with changes in gas composition due to the additional absorptive polymer layer. The findings conclude that an adequately enhanced transduction of PhC intra-cavity sensor devices is readily plausible, laying the groundwork to significantly optimize and broaden their functionality as detectors.

(a)

(b)
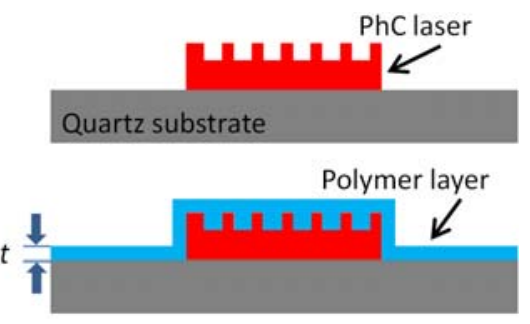

(c)

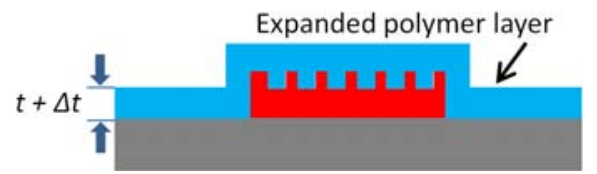

(d)

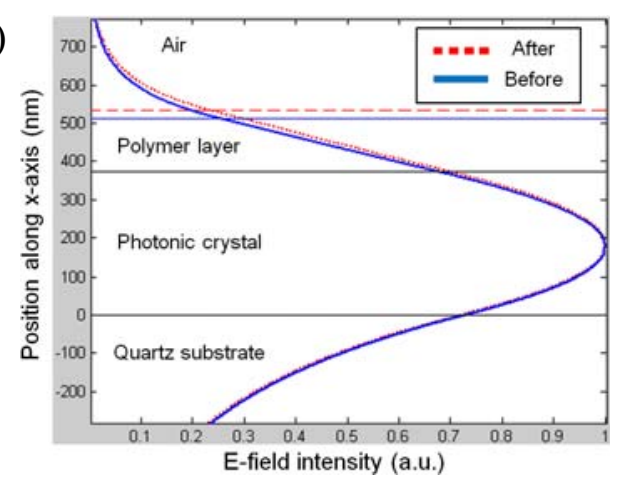

Figure 1. (a) Schematic of $\mathrm{PhC}$ band-edge laser with (b) additionally deposited polymer layer and (c) expansion of that layer due to exposure to a specific gas. (d) The four-layer system with thicknesses of the PhC, $T_{P h C}=375 \mathrm{~nm}$, and pre-expanded polymer layer, $T_{P o l}=138 \mathrm{~nm}$.

Superimposed are E-field profiles of the 0th modes for the cases before (solid) and after (dotted) the polymer layer expansion.

\section{Concept}

Figure 1 (a)-(c) illustrates the operating principle of the device. An additional polymer layer, deposited by polymerization in a pulsed AC plasma [7], covers the device surface after the initial fabrication. The polymer layer maintains a similar refractive index throughout its volume as it expands with exposure to a specific vapor, resulting in a dramatic shift of the device's ERI. The additional layer can be tailored to selectively respond to specific gases e.g. poly(styrene) (PS) has a high response to unpolar compounds such as heptane and low response to polar compounds such as water; poly(vinyl pyrrolidone) (PVP) the opposite. The devices include PhC band-edge lasers 
with rectangular lattice [8] formed in a polymer-based platform made with nanoimprint technology [9]. Polymer $\mathrm{PhC}$ lasers have previously been shown to respond to changes in refractive index of an optofluidic cladding as an intra-cavity sensor [10].

\section{Results}

Our numerical study considers the geometry shown in Fig. 1 (d), solving for mode profiles of the four-layer system. The PhC layer is treated as a uniform slab with an ERI $n_{P h C}=1.562$ and thickness $T_{P h C}=375 \mathrm{~nm}$. The refractive indices for air and the substrate are $n_{\text {air }}=1.000$ and $n_{\text {subs }}=1.462$ respectively, while their thicknesses extend to infinity. The polymer layer refractive index is approximated to remain close to its original value $\left(n_{\mathrm{PS}}=1.590\right.$; $\left.n_{P V P}=1.530\right)$ as the added volume is composed of absorbed vapor in its condensed state (e.g. ethanol: $n=1.362$ ). We study the effect of expanding the additional polymer layer by $15 \%$ of its initial volume. The polymer layer thickness before its expansion is $T_{P o l}=138 \mathrm{~nm}$.

Figure 2 (a) shows initial experimental measurements on $\mathrm{PhC}$ laser devices with a $42 \mathrm{~nm}$ thick additional polymer layer deposited. The wavelength shift observed is $\Delta \lambda=0.22 \mathrm{~nm}\left(\Delta n_{\text {eff }}=3.7 \times 10^{-4}\right)$; estimating an upper limit of refractive index change in the gas, $\Delta n_{\text {fluid }}=6 \times 10^{-4}$, this results in a sensitivity, $\Delta \lambda / \Delta n_{\text {fluid }}$, exceeding $350 \mathrm{~nm} / \mathrm{RIU}$. This value compares favorably with other liquid-based PhC intra-cavity sensors [3-5].

Figure 2 (b) displays a numerical optimisation of the deposition thickness of the additional polymer layer, plotting the change in ERI of the system versus varying the pre-exposed polymer layer thickness. The optimal thickness of the deposited layer to achieve maximum change in ERI, $\Delta n_{e f f}$, is $138 \mathrm{~nm}$, corresponding to a wavelength shift of $\Delta \lambda=0.48 \mathrm{~nm}$. The refractive index of the polymer layer in the calculation is $n_{p o l}=1.5$.

(a)

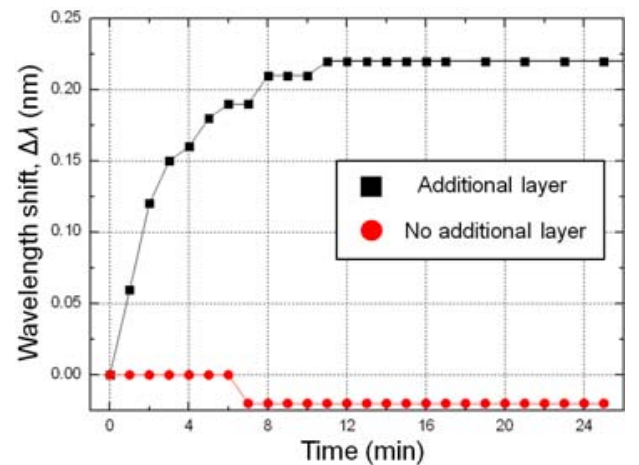

(b)

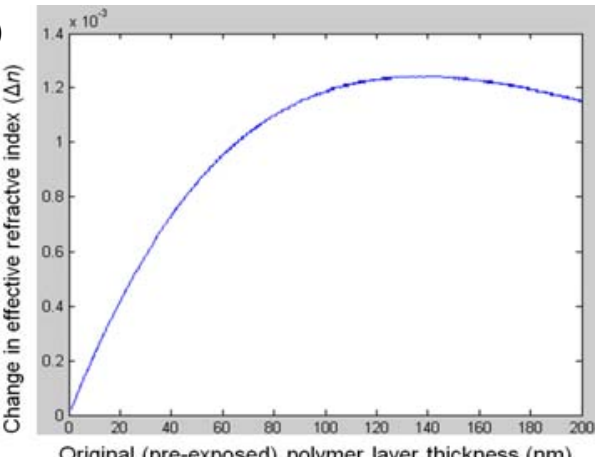

Figure 2. (a) Experimental measurement of the wavelength shift over time for ethanol vapor pressure approaching equilibrium, comparing the additional polymer layer (poly(styrene)) to the case without. (b) Change in effective index versus original polymer layer thickness for a $15 \%$ expansion of the polymer layer. Optimal thickness of the deposited layer $\left(n_{p o l}=1.5\right)$ is $138 \mathrm{~nm}$, corresponding to $\Delta \lambda=0.48 \mathrm{~nm}$.

In conclusion, we present a concept for enhanced transduction of polymer-based $\mathrm{PhC}$ band-edge lasers for intracavity sensing of gases by deposition of an additional select-absorptive polymer layer. The enhancement is achieved by the expansion of the additional polymer causing an increase in the device's ERI. This work is highly relevant for applications such as threat detection, environmental monitoring and bio-sensing.

[1] D. Erickson, T. Rockwood, T. Emery, A. Scherer, and D. Psaltis, "Nanofluidic tuning of photonic crystal circuits," Opt. Lett. 31, 59-61 (2006).

[2] N. A. Mortensen, and S. S. Xiao, "Slow-light enhancement of Beer-Lambert-Bouguer absorption," Appl. Phys. Lett. 90, 3 (2007).

[3] E. Chow, A. Grot, L. W. Mirkarimi, M. Sigalas, and G. Girolami, "Ultracompact biochemical sensor built with two-dimensional photonic crystal microcavity," Opt. Lett. 29, 1093-1095 (2004).

[4] U. Bog, C. L. C. Smith, M. W. Lee, S. Tomljenovic-Hanic, C. Grillet, C. Monat, L. O'Faolain, C. Karnutsch, T. F. Krauss, R. C. McPhedran, and B. J. Eggleton, "High-Q microfluidic cavities in silicon-based two-dimensional photonic crystal structures," Opt. Lett. 33, 2206-2208 (2008).

[5] P. S. Nunes, N. A. Mortensen, J. P. Kutter, and K. B. Mogensen, "Photonic crystal resonator integrated in a microfluidic system," Opt. Lett. 33, 1623-1625 (2008).

[6] C. Monat, P. Domachuk, and B. J. Eggleton, "Integrated optofluidics: A new river of light," Nat. Photonics 1, 106-114 (2007).

[7] Z. Ademovic, J. Wei, B. Winther-Jensen, X. L. Hou, and P. Kingshott, "Surface modification of PET films using pulsed AC plasma polymerisation aimed at preventing protein adsorption," Plasma Process. Polym. 2, 53-63 (2005).

[8] M. B. Christiansen, A. Kristensen, S. S. Xiao, and N. A. Mortensen, "Photonic integration in k-space: Enhancing the performance of photonic crystal dye lasers," Appl. Phys. Lett. 93, 3 (2008).

[9] X. Cheng, and L. J. Guo, "A combined-nanoimprint-and-photolithography patterning technique," Microelectron. Eng. 71, 277-282 (2004).

[10] M. B. Christiansen, J. M. Lopacinska, M. H. Jakobsen, N. A. Mortensen, M. Dufva, and A. Kristensen, "Polymer photonic crystal dye lasers as Optofluidic Cell Sensors," Opt. Express 17, 2722-2730 (2009). 